\title{
Magnetic resonance imaging in patients with meningitis induced hearing loss
}

\author{
J. Beijen · J. Casselman · F. Joosten · T. Stover • \\ A. Aschendorff $\cdot$ A. Zarowski $\cdot$ H. Becker $\cdot$ E. Mylanus
}

Published online: 4 April 2009

(C) Springer-Verlag 2009

\section{Erratum to: Eur Arch Otorhinolaryngol \\ DOI 10.1007/s00405-009-0921-z}

In Fig. 2 as it is printed in the article, an indication arrow is pointing to a location that does not correspond with the

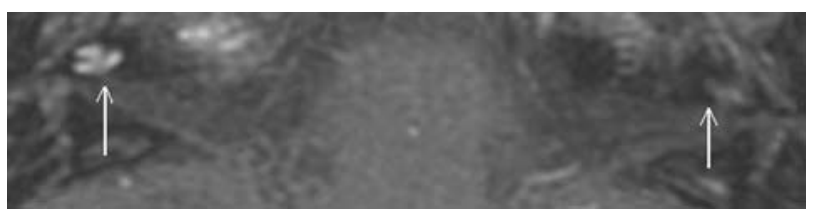
location of the cochlea. The correct Fig. 2 is given here.

The online version of the original article can be found under doi:10.1007/s00405-009-0921-z.

J. Beijen $(\bowtie) \cdot$ E. Mylanus

Department of Otorhinolaryngology,

Radboud University Medical Centre, Philips van Leydenlaan 15,

P.O. Box 9101, 6500 HB Nijmegen, The Netherlands

e-mail: j.beijen@kno.umcn.nl

J. Casselman

Department of Radiology, Academic Hospital, Bruges, Belgium

\section{F. Joosten}

Department of Radiology,

Alysis Hospital, Arnhem, The Netherlands

T. Stover

Department of Otorhinolaryngology,

Medical University of Hannover, Hannover, Germany
A. Aschendorff
Department of Otorhinolaryngology,
University Hospital of Freiburg, Freiburg, Germany

\section{A. Zarowski}

Department of Otorhinolaryngology,

Sint-Augustinus University Hospital, Antwerp, Belgium

\section{H. Becker}

Department of Neuroradiology,

Medical University of Hannover, Hannover, Germany 